\title{
As possíveis consequências do abuso sexual praticado contra crianças e adolescentes
}

\author{
Bruno Ricardo Bérgamo Florentino ${ }^{\star}$ \\ Universidade Federal de São João del-Rei, São João del-Rei, MG, Brasil
}

Resumo

\begin{abstract}
Este artigo tem como objetivo central realizar uma discussão sobre os impactos da violência sexual sobre as crianças e adolescentes. Considerando que os profissionais que lidam com esta demanda devem estar atentos para as diferentes e potenciais implicações decorrentes de tal circunstância, o presente artigo tem como objetivo realizar uma sistematização das principais contribuições teóricas pertinentes sobre o assunto e contribuir para divulgar o conhecimento já elaborado sobre as possíveis consequências de um abuso sexual na vida de uma criança ou adolescente. A sistematização dos estudos já realizados aponta que as consequências do abuso sexual são graves, extensas e diversas.
\end{abstract}

Palavras-chave: abuso sexual; crianças; adolescentes; consequências.

\section{The possible consequences of the sexual abuse practised against children and adolescents}

\begin{abstract}
The central aim of this article is realize a discussion about the impacts of sexual violence against children and adolescents. Taking into consideration that the professionals who deal with this demand must be attentive to the different and potential implications due to that circumstance, this article aims at realizing a systematization of the main theoretical contributions relevant to this issue and contribute to divulge the knowledge which has already been elaborated about the possible consequences of a sexual abuse against a child or adolescent. The systematization of previous studies show that the consequences of sexual abuse are serious, extensive and diverse.
\end{abstract}

Keywords: sexual abuse; children; adolescents; consequences.

\section{Introdução}

A violência contra a criança e o adolescente é um problema universal que atinge milhares de vítimas de forma silenciosa e dissimulada. Trata-se, deste modo, de um problema que acomete ambos os sexos e não costuma obedecer nenhuma regra como nível social, econômico, religioso ou cultural (BALLONE; ORTOLANI; MOURA, 2008; CUNHA; SILVA; GIOVANETTI, 2008; DEL PRIORE, 2007; FREITAS, 1997; PRADO, 2004; ROMARO; CAPITÃO, 2007).

A violência doméstica, segundo Adorno (1988), é uma forma de relação social que está diretamente relacionada ao modo pelo qual os homens produzem e reproduzem suas condições sociais de existência. Ao mesmo tempo, ela é a negação de valores considerados universais, como liberdade, igualdade e a própria vida. Neste processo, a criança e o adolescente são as maiores vítimas de atos abusivos e maus-tratos, ocasionados por sua maior vulnerabilidade e dependência.

Já a violência sexual, caracteriza-se por atos praticados com finalidade sexual que, por serem lesivos ao corpo e a mente do sujeito violado (crianças e adolescentes), desrespeitam os direitos e as garantias individuais como liberdade, respeito e dignidade previstos na Lei $\mathrm{n}^{\circ}$ 8.069/90 - Estatuto da Criança e do Adolescente (BRASIL, 1990, Artigos $7^{\circ}, 15,16,17$ e 19).

\footnotetext{
^Endereço para correspondência: Universidade Federal de São João Del Rei Praça Dom Helvécio, 74. Programa de Pós-Graduação em Psicologia. Sala 1.53. E-mail: bruno_psicologia@hotmail.com
}

A violência sexual caracteriza-se:

[...] por um ato ou jogo sexual, em uma relação heterossexual ou homossexual, entre um ou mais adultos e uma criança ou adolescente, tendo por finalidade estimular sexualmente esta criança ou adolescente, ou utilizá-la para obter uma estimulação sexual sobre sua pessoa ou de outra pessoa (AZEVEDO; GUERRA, 1998, p.33).

Destaca-se que a violência sexual pode ser compreendida a partir de duas especificidades/peculiaridades: exploração sexual e abuso sexual - sendo este último o objeto de interesse do presente artigo.

A exploração sexual caracteriza-se pela relação mercantil, mediada pelo comércio do corpo/sexo, por meios coercitivos ou não, e se expressa de quatro formas: pornografia, tráfico, turismo sexual e prostituição.

O abuso sexual caracteriza-se por qualquer ação de interesse sexual de um ou mais adultos em relação a uma criança ou adolescente, podendo ocorrer tanto no âmbito intrafamiliar - relação entre pessoas que tenham laços afetivos, quanto no âmbito extrafamiliar - relação entre pessoas que não possuem parentesco.

A primeira categoria do abuso sexual, definida anteriormente, também pode ser entendida como incesto, que, comumente, dura um longo período e pode ser praticado com o conhecimento e cobertura de outros membros da família. Em nossa cultura, o incesto é uma das formas de abuso sexual mais frequente, sendo este o que geralmente causa consequências - em nível psíquico extremamente danosas às vítimas. 
Nesse sentido, é fundamental buscar na literatura elementos que possam iluminar e apontar para algumas consequências decorrentes do abuso sexual infanto-juvenil, com o objetivo de entender o seu impacto no desenvolvimento da criança.

O que se observa na literatura existente é a concordância entre os especialistas em reconhecer que a criança vítima de abuso e de violência sexual corre o risco de uma psicopatologia grave, que perturba sua evolução psicológica, afetiva e sexual (ROMARO; CAPITÃO, 2007, p. 144).

\section{Metodologia}

O presente trabalho foi construído com base em pesquisa bibliográfica, que, de acordo com Gil (1991, p. 48):

é desenvolvida a partir de material já elaborado, constituído principalmente de livros e artigos científicos. Embora em quase todos os estudos seja exigido algum tipo de trabalho desta natureza, há pesquisas desenvolvidas exclusivamente a partir de fontes bibliográficas.

Este artigo foi realizado com base em estudos qualitativos-descritivos, cujo objetivo principal "é delinear ou analisar as características de um fenômeno" (CAMPOS, 2000, p. 54). Para elaboração do trabalho, foram utilizadas obras de história, psicologia, sociologia, serviço social e direito, caracterizando a pesquisa documental.

A pesquisa documental, por exemplo, é aquela que utiliza de documentos, escritos ou não, como fonte primária de dados. É uma pesquisa característica das Ciências Humanas. Abrange todas as informações já tornadas públicas em relação ao tema, e tem como finalidade colocar o pesquisador em contato direto com tudo o que foi dito, escrito ou filmado sobre determinado assunto (CAMPOS, 2000, p. 53).

A metodologia seguiu as etapas de leitura, fichamentos e interpretação das referências.

\section{O abuso sexual e suas potenciais consequências no desenvolvimento infanto-juvenil}

De acordo com Kaplan e Sadock (1990), os maus-tratos na infância representam uma doença médico-social que está assumindo proporções epidêmicas na população mundial. $\mathrm{O}$ abuso sexual de crianças e adolescentes é um dos tipos de maus-tratos mais frequentes, apresentando implicações médicas, legais e psicossociais que devem ser cuidadosamente estudadas e entendidas pelos profissionais que lidam com esta questão.

Diversos estudos demonstram que as consequências do abuso sexual infanto-juvenil estão presentes em todos os aspectos da condição humana, deixando marcas - físicas, psíquicas, sociais, sexuais, entre outras - que poderão comprometer seriamente a vida da vítima (criança ou adolescente) que passou por determinada violência (ABRAPIA, 1997; CUNHA; SILVA; GIOVANETTI, 2008; FURNISS, 1993; GABEL, 1997; KAPLAN; SADOCK, 1990; PRADO, 2004; ROMARO; CAPITÃO, 2007; SILVA, 2000).
Pode-se afirmar que o abuso sexual e suas consequências sobre a saúde da vítima "são primeiramente uma violação dos direitos humanos, não escolhendo cor, raça, credo, etnia, sexo e idade para acontecer" (CUNHA; SILVA; GIOVANETTI, 2008, p. 245).

Os sintomas atingem todas as esferas de atividades, podendo ser simbolicamente a concretização, ao nível do corpo e do comportamento, daquilo que a criança ou o adolescente sofreu. Ao passar por uma experiência de violação de seu próprio corpo, elas reagem de forma somática independentemente de sua idade, uma vez que sensações novas foram despertadas e não puderam ser integradas (PRADO, 2004 p. 64).

Compreender e avaliar a extensão das consequências do abuso sexual infanto-juvenil não é um trabalho fácil, pois existe uma enorme carência de estudos longitudinais que se proponham a acompanhar as vítimas por um longo prazo. Isso se dá em função da ausência de grupos de controle ${ }^{1}$ apropriados; por isso, o pouco conhecimento (existente na literatura) que se tem sobre as consequências deste tipo de violência, foi construído a partir do relato de algumas pessoas isoladas que procuraram ajuda e a partir dos profissionais e estudiosos que interviram junto aos mesmos.

Contudo,

A maioria dos pesquisadores concorda que o abuso sexual infantil é facilitador para o aparecimento de psicopatologias graves, prejudicando a evolução psicológica, afetiva e social da vítima. Os efeitos do abuso na infância podem se manifestar de várias maneiras, em qualquer idade da vida (ROMARO; CAPITÃO, 2007, p. 151).

Ao debater as consequências do abuso sexual infanto-juvenil, é necessário considerar algumas particularidades que envolvem a violência praticada, tais como: grau de penetração; acompanhamento de insultos ou violência psicológica; uso de força ou violência física, entre outras brutalidades que, obviamente, são variações que comprometem as conclusões sobre as consequências do abuso sexual.

Furniss (1993) afirma que as consequências ou o grau de severidade dos efeitos do abuso sexual variam de acordo com algumas condições ou predeterminações de cada indivíduo, dentre eles: a idade da criança ${ }^{2}$ quando houve o início da violência; a duração e quantidade de vezes em que ocorreu o abuso, ${ }^{3}$ o grau de violência utilizado no momento da situação; a diferença de idade entre a pessoa que cometeu e a que sofreu o abuso; se existe algum tipo de vínculo ${ }^{4}$ entre o abusador e a vítima; o acompanhamento de ameaças (violência psicológica) caso o abuso seja revelado.

${ }^{1}$ Acreditamos que isto ocorre, uma vez que quem sofreu abuso sexual deseja esquecer do acontecimento, não quer ficar revivendo ou sendo acompanhado como parte de um "grupo de controle" que pretende avaliar se as pessoas estão tendo reações tardias de uma experiência traumática como a do abuso sexual.

${ }^{2}$ Embora se saiba que a idade da criança é um fator que interfere no tipo de comprometimento que a criança pode desenvolver, não se sabe em qual idade há maior ou menos prejuízo.

${ }^{3}$ Algumas evidências apontam que maior período de tempo houver o abuso, maior será a produção de consequências negativas.

${ }^{4}$ Caso exista vínculo entre o abusador e a vítima, outro fator que compromete as consequências é a qualidade desta relação existente. 
Day et al. (2003) citam algumas possíveis manifestações psicológicas decorrentes da violência doméstica ${ }^{5}$ que ocorrem a curto e longo prazo. Em seu estudo, as potenciais manifestações em curto prazo são: medo do agressor e de pessoas do sexo do agressor; queixas sintomáticas; sintomas psicóticos; isolamento social e sentimentos de estigmatização; quadros fóbico-ansiosos, obsessivo-compulsivo, depressão; distúrbios do sono, aprendizagem e alimentação; sentimentos de rejeição, confusão, humilhação, vergonha e medo; secularização excessiva, como atividades masturbatórias compulsivas. Já os danos tardios podem se manifestar através de ocorrência e incidência de transtornos psiquiátricos como dissociação afetiva, pensamentos invasivos, ideação suicida e fobias mais agudas; níveis mais intensos de medo, ansiedade, depressão, raiva, culpa, isolamento e hostilidade; sensação crônica de perigo e confusão, cognição distorcida, imagens distorcidas do mundo e dificuldade de perceber a realidade; pensamento ilógico; redução na compreensão de papéis mais complexos e dificuldade para resolver problemas interpessoais; abuso de álcool e outras drogas; disfunções sexuais; disfunções menstruais e homossexualismo/lesbianismo.

Ao discorrer sobre as consequências do abuso sexual praticado contra crianças e adolescentes, é essencial pensar o quanto é monstruosa a deturpação da condição física, biológica ou orgânica, ${ }^{6}$ pois o abuso sexual compreende uma violação do corpo da vítima que, muitas vezes, sai com ferimentos na própria pele. ${ }^{7}$ Desta forma, é possível apontar como consequências orgânicas: lesões físicas gerais; lesões genitais; lesões anais; gestação, doenças sexualmente transmissíveis; disfunções sexuais; hematomas; contusões e fraturas. Usualmente, a vítima sofre com ferimentos advindos de tentativas de enforcamento; lesões genitais que não se dão somente pela penetração e sim por meio da introdução de dedos e objetos no interior da vagina das vítimas; lesões que deixam manifesto o sadismo do agressor, como queimaduras por cigarro, por exemplo; lacerações dolorosas e sangramento genital; irritação da mucosa da vagina; diversas lesões anais, tais como a laceração da mucosa anal, sangramentos e perda do controle esfincteriano em situações onde ocorre aumento da pressão abdominal.

Gabel (1997 p. 67) descreve diversas queixas somáticas que são habituais após a ocorrência de abusos sexuais em crianças e adolescentes, as quais se manifestam na forma de mal-estar difuso; impressão de alterações físicas; persistência das sensações que lhe foram impingidas; enurese e encoprese; dores abdominais agudas; crises de falta de ar e desmaios; problemas relacionados

\footnotetext{
Como não existem muitos estudos específicos das consequências do abuso sexual, buscamos referências na literatura de violência doméstica, entendendo que o abuso sexual é uma especificidade de tal violência, portanto, ao se referir sobre violência doméstica, os autores também estão se referindo ao abuso sexual.

${ }^{6}$ Embora as consequências biológicas do abuso sexual possam parecer distante do debate da psicologia, elas necessitam ser mencionadas, uma vez que a presença de lesões no corpo é um componente que certamente interfere no modo de vivenciar a experiência e agrava os comprometimentos subjetivos.

Pele no sentido de corpo, objeto, matéria viva e orgânica e não somente a pele no sentido de tecido corporal.
}

à alimentação como náuseas, vômitos, anorexia ou bulimia; interrupção da menstruação mesmo quando não houve penetração vaginal.

No campo da neurologia, existem pesquisas e estudos sustentando hipóteses de que situações de violência e abuso sexual podem acarretar em danos temporários ou permanentes na estrutura do cérebro, como mostra a citação a seguir:

Procurando observar o efeito sobre o sistema límbico de pessoas que haviam sofrido abuso na infância, utilizou a técnica da coerência em eletroencefalograma, um sofisticado método de análise quantitativa que fornece evidências sobre a microestrutura do cérebro. Comparou 15 voluntários saudáveis com 15 pacientes psiquiátricos, crianças e adolescentes, que tinham histórico confirmado de intenso abuso físico ou sexual. Medidas de coerência mostraram que os córtex esquerdos dos jovens do grupo controle eram mais desenvolvidos que os direitos. Já os pacientes que haviam sofrido maus-tratos possuíam o córtex direito claramente mais desenvolvido, embora todos fossem destros e, portanto, tinham o córtex esquerdo dominante. A hipótese resultante foi a de que as crianças maltratadas teriam armazenado suas memórias perturbadoras no hemisfério direito e a ativação de tais memórias poderia ativá-lo preferencialmente (TEICHER, 2002 apud ROMARO; CAPITÃO, 2007 p. 143).

Apesar da discussão apresentada a partir dos aspectos psiquiátricos, biológicos e neurológicos, considera-se que "a questão do trauma psíquico, evidentemente, está no cerne da situação do abuso sexual" (GABEL, 1997, p. 206).

Neste sentido, retoma-se a discussão para o campo subjetivo, debatendo uma questão que, imediatamente, praticamente todas as vítimas de abuso sexual passam após a situação abusiva - estresse pós-traumático ou Transtorno de Estresse Pós-Traumático, como costuma ser nomeado por alguns autores. $\mathrm{O}$ transtorno de estresse pós-traumático - TEPT $^{8}$ - está ligado a experiências incomuns da existência humana que causam um impacto emocionalmente severo no indivíduo, deixando consequências que afetam a saúde física e mental.

Silva (2000) fez uma revisão da literatura sobre os efeitos da desordem do estresse pós- traumático e apontou seis elementos comuns a pessoas que experimentaram o TEPT: reexperimentação de memórias intrusivas e persistentes ligadas ao trauma; exposições compulsivas a situações que lembram o trauma; impedimento incessante à exposição de situações específicas, usualmente ligadas à emoção do trauma experimentado e um entorpecimento às reações emocionais, de modo geral; diminuição da capacidade de usar linguagem falada, substituindo esta por gestos como guia para a ação; distúrbios ligados à desatenção, tais como desconcentração, discriminação de estímulo, alterações no mecanismo da defesa psicológica e na identidade pessoal; e, por último, alterações na identidade pessoal.

${ }^{8}$ Prado (2004, p. 148) caracteriza o Transtorno de Estresse Pós Traumático como uma entidade nosológica desenvolvida após um evento traumático, tratando-se de um transtorno de ansiedade que surge como uma resposta imediata ou tardia a um evento estressante de natureza excepcionalmente ameaçadora, como o abuso sexual, por exemplo. 
De acordo com Flores e Caminha (1994), as principais manifestações do TEPT são divididas em três grupos: reexperimentação dos fenômenos - lembranças intrusas, sonhos traumáticos, comportamento de reconstituição, angústia nas lembranças traumáticas; evitação psicológica - fuga de sentimentos, pensamentos, locais e situações, interesse reduzido em atividades habituais, sentimento de estar sozinho, âmbito emocional restrito, transtorno de memória, perda de habilidades já adquiridas, alteração na orientação com respeito ao futuro; e estado de excitação aumentada - transtorno do sono, irritabilidade, raiva, dificuldade de concentração, hipervigilância, resposta exagerada de sobressalto e resposta autônoma a lembranças traumáticas.

Os sintomas construídos durante uma experiência traumática afetam não somente os pensamentos do indivíduo, mas a sua memória, o estado de consciência e todo o campo de ação, de iniciativa e de objetividade na vida. Muitas vítimas criam uma área de proteção em volta de si que as impede de continuar com a vida normal. Uma vítima de violência física, seja ela estupro ou pancadas, evita sair de casa, tem medo de andar sozinha, rejeita sexo ou qualquer contato físico (SILVA, 2000, p. 32).

Silva (2000) afirma que o modo como a pessoa reage diante de uma situação traumática depende da capacidade que ela possui em regular os efeitos advindos da situação. Se o indivíduo é capaz de regular os efeitos, é capaz de continuar com certo controle sobre a vida, mesmo depois do trauma. Para o autor, existem pessoas que acreditam que o ser humano é capaz de controlar o trauma (até certo ponto); todavia, este pensamento de um controle total sobre a vida é uma posição decididamente otimista, mas não muito realista.

Outra situação que compromete a vida das crianças e adolescentes vítimas de abuso sexual é o segredo. O segredo carrega uma proibição de verbalizar os fatos que é explícita em certos casos, mas pode ser ligada ao modo de comunicação não-verbal, predominantemente quando o abuso e abusador estão no meio familiar. Esta vítima busca manter o segredo das situações vividas, seja por temor de sofrer sanções e castigos por ambos os genitores, seja por sentir sobre seus ombros a responsabilidade de manter o equilíbrio e integridade da família.

Com relação à vítima, pode-se afirmar que o silenciamento diante de uma situação que lhe viola, oprime, envergonha e, muitas vezes, desumaniza, constitui uma reação natural à situação vivenciada, posto tratar-se de um "cidadão em condições especiais de desenvolvimento", submetido a uma relação assimétrica de poder (física e/ou psicológica) que, muitas vezes, se estende para além do controle e domínio da vítima propriamente dita (CUNHA; SILVA; GIOVANETTI, 2008, p. 283).

Prado (2004) ratifica a afirmação de que o segredo permanece causando diversos comprometimentos psicológicos, alimentados por uma angústia dupla: não contar por temer o agressor e não contar por temer não ser acreditada pela genitora ou pelo restante da família. Em seu silêncio, é possível perceber que, ao mesmo tempo em que a vítima não denuncia o agressor, ela também para- lisa, não se protegendo por outros meios como se faltassem recursos mediadores para isso. Dependendo da idade da vítima, muitas vezes o recurso mediador passa pela ordem simbólica, podendo ser aquilo que ela é capaz de mostrar ou dizer com suas palavras ou comportamentos.

Observa-se que o pacto de silêncio que se estabelece nos casos de abuso sexual contra crianças é um entrave para que este seja impedido e os agressores punidos. A falta de punição e a recorrência do ato sexual violento podem, muitas vezes, levar a criança à morte ou deixar graves seqüelas físicas e psíquicas (ROMARO; CAPITÃO, 2007, p. 171).

Gabel (1997) afirma que quando uma criança tem oportunidade de revelar este segredo, recebendo crédito e ajuda de profissionais, por exemplo, as manifestações mais notórias desaparecem. Isso faz com que a criança ou $\mathrm{o}$ adolescente reencontre o interesse por si, pelos outros e pela brincadeira, ainda que a angústia possa se desdobrar em outras formas de neurose, incluindo diversas fobias: medo do escuro, da solidão; agorafobia; afastamento da família, dos amigos, das pessoas do mesmo sexo.

A reflexão estabelecida até o presente momento parece denunciar a gravidade do fenômeno, uma vez que as conseqüências deste para a vitima podem ser traumáticas. O abuso sexual, sendo ele de caráter incestuoso ou não, deixa a criança numa sensação de total desamparo. $O$ adulto que deveria ser sinônimo de proteção se torna fonte de perturbação e ameaça. Ela não tem com quem contar, não pode comentar o fato e ainda é mobilizada, pela complexidade da relação, a sentir-se culpada. O silêncio, portanto, pode estar associado ao sentimento de culpa, às ameaças feitas, ao vínculo estabelecido na relação, principalmente por parte da criança (ROMARO; CAPITÃO, 2007, p. 180).

É possível afirmar que a criança ou adolescente facilmente encontrará razões para se sentir culpada diante de uma situação de abuso sexual. Por isso, é essencial ouvir a criança e permitir que se expresse ao nível de sua culpa, pois o que ela pode dizer e sentir no plano consciente, e também no inconsciente, talvez seja muito diferente de nossas projeções e de nossa lógica enquanto adultos.

Sentimentos de culpa são corriqueiros entre crianças e adolescentes sexualmente abusadas, sendo a culpa um dos efeitos emocionais mais severos que resultam da interação abusiva, especialmente se esta foi incestuosa e durou por muito tempo. Quanto ao sentimento de culpa, soma-se o dano secundário da estigmatização, devido à acusação por parte dos pais e da família (FURNISS, 1993).

A violência sexual contra crianças e adolescentes segundo Vaz (2001), ocorre, muitas vezes, no seio familiar ou em locais próximos, como vizinhança ou casa de parentes. A violência na maior parte dos casos não é denunciada e há a omissão de parentes ou conhecidos quanto ao crime cometido. Tal violência deixa "feridas afetivas" na criança que não são cicatrizadas, uma vez que o ato é praticado por alguém que a criança confia (ROMARO; CAPITÃO, 2007, p. 157).

Como dito anteriormente, as consequências do abuso sexual variam de acordo com o elo que une a criança e aquele que abusou dela. Na maior parte dos casos, o in- 
cesto tem consequências mais severas e duradouras. Isso porque provoca uma confusão em relação às imagens parentais: o pai deixa de desempenhar um papel protetor e representante da lei, associado à debilidade e omissão da mãe diante do ato (GABEL, 1997).

Nos casos de abuso sexual intrafamiliar, a família, que deveria representar um local seguro para os seus membros, torna-se um espaço de insegurança, medo, desconfiança, conflitos e de incertezas entre o que é certo e errado. Percebe-se que há uma inversão de papéis, nos quais a criança ou adolescente é colocada no lugar de parceiro pseudo-igual no relacionamento sexual e os papéis familiares passam a ser vivenciados de forma confusa, descaracterizando a família como o lugar de crescimento, confiança e apoio - o que acarretará enormes prejuízos ao desenvolvimento da criança ou adolescente (FURNISS, 1993; GABEL, 1997; ROMARO; CAPITÃO, 2007).

Quanto ao comportamento social das vítimas, sabe-se que o abuso sexual compromete as crianças e adolescentes de maneira estrondosa, destruindo o modo de se relacionar e confiar em outras pessoas. Flores e Caminha (1994) apresentam um estudo no qual os resultados mostram que as crianças e adolescentes abusadas possuem menor comportamento pró-social: compartilham menos, ajudam menos e se associam menos a outras crianças, quando comparadas com crianças não abusadas; retraimento; relacionamentos superficiais.

As diversas formas de violência ou abuso afetam a saúde mental da criança ou do adolescente, visto este se encontrar em um processo de desenvolvimento psíquico e físico, produzindo efeitos danosos em seu desempenho escolar, em sua adaptação social, em seu desenvolvimento orgânico. Vários estudos relacionam a violência doméstica com o desenvolvimento de transtornos de personalidade, transtorno de ansiedade, transtornos de humor, comportamentos agressivos, dificuldades na esfera sexual, doenças psicossomáticas, transtorno de pânico, entre outros prejuízos, além de abalar a auto-estima, por meio da identificação com o agressor, um comportamento agressivo (ROMARO; CAPITÃO, 2007, p. 121).

O comportamento sexual inadequado pode ser considerado como outro sintoma muito característico de crianças sexualmente abusadas. O comportamento sexual inapropriado é caracterizado por brinquedo ou brincadeiras de cunho sexual com bonecas; introduzir objetos ou dedos no ânus ou na vagina; masturbação excessiva; comportamento sedutor; conhecimento sexual inapropriado para a idade e pedido de estimulação sexual para adultos ou outras crianças. Um exemplo deste tipo de situação está exemplificado no seguinte relato:

Paul, de cinco anos, foi rapidamente confiado a uma família adotiva, com apoio do Estado, depois que foi sodomizado por seu padrasto; a mãe adotiva não quis mais acolhê-lo depois de tê-lo surpreendido com seu filho de três anos, reproduzindo com um objeto o que ele havia sofrido. Descobrimos, às vezes, reações em cadeia: Cécile, de seis anos, foi denunciado por um vizinho, de dez anos, ao qual ele pediu que se despisse. Nesse momento, tomou-se conhecimento de que tinha sido obrigada a praticar uma relação em um adolescente de catorze anos, ele próprio vítima de um professor. Enfermeiros e professoras de cursos maternais descrevem o mal-estar por que passam diante de crianças que procuram contato erótico e lhes pedem carícias genitais. Essas provocações, muito freqüentes depois de um abuso sexual, farão com que as pessoas achem que a criança é perversa e que mente quando denuncia aquilo que lhe aconteceu (GABEL, 1997, p. 69).

Entre adolescentes, é possível detectar a agressão sexual sobre outras crianças, especialmente no caso de meninos que sofreram agressões sexuais na pré-puberdade. Já entre as meninas, é comum observar uma tendência à repetição do que sofreram, através de comportamentos que se manifestam em atitudes de sedução. Nos casos mais extremos, é possível verificar a ocorrência de situações consideradas perversas, nas quais, de certa forma, algumas vítimas de abuso sexual podem pender para a ninfomania e até mesmo prostituição (GABEL, 1997).

Romaro e Capitão (2007) fazem referência a outros tipos de transtornos que podem ser causados pelo abuso sofrido na infância ou adolescência. Trata-se das disfunções sexuais como a falta ou perda do desejo sexual que inclui a frigidez, aversão sexual e falta de prazer sexual, falha de resposta genital incluindo a impotência sexual, a disfunção orgástica (que é o orgasmo inibido), a ejaculação precoce (incapacidade de controlar a ejaculação o suficiente para ambos os parceiros gozarem a interação sexual), o vaginismo não orgânico (espasmo do músculo que circunda a vagina, causando oclusão da abertura vaginal), a dispaurenia não orgânica (dor durante o intercurso sexual) e a ninfomania (impulso sexual excessivo).

Não obstante, os resultados de uma pesquisa internacional revelam que as consequências do abuso sexual podem se manifestar em curto prazo (infância) e a longo prazo (adolescência e idade adulta), sendo os principais sintomas ou sinais perceptíveis através de manifestações de alta atividade sexual; confusão e ansiedade a respeito da identidade sexual para aqueles que sofreram abuso homossexual, especialmente vítimas do sexo masculino; dificuldades no ajustamento sexual adulto (dificuldades conjugais, impotência, ansiedade sexual, menor satisfação sexual, evitação de sexo ou desejo compulsivo por sexo); e confusão quanto aos valores sexuais (ROMARO; CAPITÃO, 2007).

Dalgalarrondo (2000) indica que alguns estudos apresentam resultados que confirmam existir uma forte relação entre ter sofrido abuso na infância e transtornos de conduta na adolescência e na vida adulta. Alguns transtornos são classificados como transtorno de identidade de gênero. Há também os transtornos de preferência sexual, que incluem as parafilias como fetichismo (dependência de alguns objetos inanimados com estímulo para a excitação e satisfação sexual); voyerismo (excitação sexual em olhar pessoas envolvidas em comportamentos sexuais ou íntimos); sadomasoquismo (preferência por atividade sexual que envolve servidão ou a influição de dor ou humilhação); pedofilia (preferência sexual por crianças 
púberes); e outras, conforme descritas na Classificação de Transtornos Mentais e de Comportamento - CID - 10 (ORGANIZAÇÃO MUNDIAL DE SAÚDE, 1993).

\section{Considerações finais}

Conforme apontado por meio da sistematização dos estudos de diversos autores, as consequências do abuso sexual são extensas e diversas para as vítimas. Diferentes autores abordam a temática sob os mais singulares pontos de vista. Médicos, psiquiatras, psicólogos, sociólogos e outras categorias profissionais já tentaram, e continuam tentando, delinear quais são as consequências decorrentes de uma situação de abuso sexual infanto-juvenil, para que, assim, se construam propostas de intervenções mais específicas no sentido de minimizar os danos dessa violência.

Dada à brutalidade em que ocorre o abuso sexual, muitas vezes associado a outros tipos de violência, tais como a violência física e a violência psicológica, justaposto ao fato de que a criança não está preparada - do ponto de vista emocional e físico - para o ato sexual, por se constituir como sujeito em condição peculiar de desenvolvimento, é quase que certo que ela desenvolva diversos tipos ou manifestações das consequências anteriormente citadas.

Em suma: não é possível generalizar ou delimitar perfeitamente os efeitos do abuso sexual, uma vez que a gravidade e a extensão das consequências dependem de particularidades da experiência de cada vítima. Dentro desta perspectiva, é importante pensar o assunto sob a ótica da singularidade de cada indivíduo - criança ou adolescente - para não cair em num reducionismo ou generalismo da questão. Cada criança ou adolescente que sofre abuso sexual é uma potencial vítima de uma ou mais consequências descritas anteriormente. Por isso, é importante que o psicólogo que venha a deparar-se com tais casos - em alguma política pública ou em consultórios particulares - tenha a sensibilidade necessária e esteja capacitado para enfrentar essa situação extremamente complexa e desafiadora.

\section{Referências}

ABRAPIA. Maus-tratos contra crianças e adolescentes: proteção e prevenção. Guia de orientação para profissionais de saúde. Petrópolis: Autores \& Associados, 1997.

ADORNO, S. Os aprendizes do Poder: o bacharelismo liberal na política brasileira. Rio de Janeiro: Paz e Terra, 1998.

AZEVEDO, M. A.; GUERRA, V. N. A. Pele de asno não é só história... um estudo sobre a vitimização sexual de crianças e adolescentes em família. São Paulo: Rocca, 1998.

BALLONE, G. J.; ORTOLANI, I. V., MOURA, E. C. Violência Doméstica. In: PsiqWeb. 2008. Disponível em: <http://www. psiqweb.med.br/site/?area=NO/LerNoticia\&idNoticia=89>. Acesso em: 18 jul. 2009.

BRASIL. Presidência da República. Casa Civil. Subchefia para Assuntos Jurídicos. Lei $n^{\circ}$ 8.069, de 13 de julho de 1990. Dispõe sobre o Estatuto da Criança e do Adolescente e dá outras providências. 1990. Disponível em: <http://www.planalto.gov. br/ccivil 03/leis/18069.htm>. Acesso em: 20 fev. 2012.

CAMPOS, L. F. de L. Métodos e técnicas de pesquisa em psicologia. Campinas, SP: Alínea, 2000.

CUNHA, E. P.; SILVA, E. M.; GIOVANETTI, A. C. Enfrentamento à violência sexual infanto-juvenil: expansão do PAIR em Minas Gerais. Belo Horizonte: UFMG, 2008.

DAlgalarRondo, P. Psicologia e Semiologia dos Transtornos Mentais. Porto Alegre: Artmed, 2000.

DAY, V. P. et al. Violência doméstica e suas diferentes manifestações. Revista de Psiquiatria do Rio Grande do Sul, Porto Alegre, v. 25, suppl. 1, p. 09-21, 2003.

DEL PRIORE, M. História das crianças no Brasil. 6. ed. São Paulo: Contexto, 2007.

FLORES, R. Z.; CAMINHA, R. M. Violência sexual contra crianças e adolescentes: algumas sugestões para facilitar o diagnóstico correto. Rev. psiquiatr. Rio Gd. Sul, Porto Alegre, v. 16, n. 2, p. 158-167, 1994.

FREITAS, M. C. (Org.). História social da infância no Brasil. São Paulo: Cortez, 1997.

FURNISS, T. Abuso Sexual da Criança: uma abordagem multidisciplinar. Porto Alegre: Artes Médicas, 1993.

GABEL, M. Crianças vítimas de abuso sexual. São Paulo: Summus, 1997.

GIL, A. C. Como elaborar projetos de pesquisa. 3. ed. São Paulo: Atlas, 1991.

KAPLAN, H. I.; SADOCK, B. J. Compêndio de psiquiatria. 2. ed. Tradução de Maria Cristina Monteiro e Daise Batista. Porto Alegre: Artes Médicas, 1990.

ORGANIZAÇÃO MUNDIAL DE SAÚDE (OMS). Classificação de Transtornos Mentais e de Comportamento da CID-10: descrições clínicas e diretrizes diagnósticas. Porto Alegre: Artes Médicas, 1993.

PRADO, M. C. C. A. (Org.). O mosaico da violência. São Paulo: Vetor, 2004.

ROMARO, R. A; CAPITÃo, C. G. As faces da violência: aproximações, pesquisas, reflexões. São Paulo: Vetor, 2007.

SILVA, I. R. Abuso e trauma. São Paulo: Vetor, 2000.

Recebido em: 21 de abril de 2012 Aceito em: 25 de março de 2015 